Molecules 2001, 6, 472-476

molecules

ISSN 1420-3049

http://www.mdpi.org

\title{
Generation and Cycloaddition of o-Quinodimethane in Aqueous Medium
}

\section{Lothar W. Bieber* and Margarete F. da Silva}

Departamento de Química Fundamental, Universidade Federal de Pernambuco, Cidade Universitária, 50670-901 Recife - PE, Brazil

*Author to whom correspondence should be addressed; e-mail: lothar@dqfex.ufpe.br

Received: 9 March 2001; in revised form 24 April 2001 / Accepted: 24 April 2001 / Published: 30 April 2001

\begin{abstract}
Quinodimethane can be generated from $\alpha, \alpha^{\prime}$-dihalo-o-xylenes using zinc in aqueous solution. In the presence of activated dienophiles cycloadducts can be obtained directly. Catalysis with tris-triphenylphosphine ruthenium(II) dichloride reduces side reactions such as reduction and polymerisation and improves the yield. This is the first example of an organometallic cyclisation in aqueous medium using dihalo compounds.
\end{abstract}

Keywords: Dehalogenation, zinc, Diels-Alder reaction, Ru catalysis, aqueous solvent

\section{Introduction}

o-Quinodimethanes (o-xylylenes) are reactive intermediates widely used for the synthesis of polycyclic compounds via inter- or intramolecular Diels-Alder reactions [1]. Because of their high reactivity and thermal instability they must be generated in situ by various methods: dehalogenation of $\alpha, \alpha^{\prime}$-dihalo-o-xylenes, thermal or photochemical extrusion of stable molecules or ring opening of benzocyclobutenes. The unsubstituted parent compound, generated at low temperature, has been proven to exist in a singlet ground state [2]. To our knowledge, all synthetic or mechanistic work in 
this field has been performed in organic solvents under anhydrous conditions. Recent progress in aqueous Diels-Alder cycloadditions and organometallic reactions [3], especially the successful Wurtz coupling of benzylic halides [4] and their Barbier addition to carbonyl compounds [5], prompted us to study the behaviour of $\alpha, \alpha^{\prime}$-dihalo-o-xylenes (1) under similar conditions in the hope to obtain benzocyclobutene (2) or, in the presence of dienophiles, cycloadducts of o-quinodimethane.

\section{Results and Discussion}

The reaction of the dibromo compound 1a with zinc dust in saturated aqueous ammonium chloride was complete in a few minutes at r.t. and produced a polymeric material 3 containing $67 \%$ of $\mathrm{C}-\mathrm{C}$ coupled methylene groups and $28 \%$ of methyl groups as a result of reduction; only trace amounts of o-xylene and dimeric or trimeric coupling products, but no 2 at all could be detected by GC/MS (Table 1, entry 1). These results agree rather well with those obtained by Alder under anhydrous conditions in DMF [6]. The reaction of the dichloride $\mathbf{1 b}$ was much slower $(1 \mathrm{~h})$, but gave a very similar product composition (entry 2). Use of metal catalysts such as $\mathrm{CuCl}_{2}, \mathrm{CuI}, \mathrm{AgNO}_{3}$ and $\mathrm{Pb}(\mathrm{OAc})_{2}$, which had an important influence on the reactivity of benzylic monohalides [4], brought no significant change.

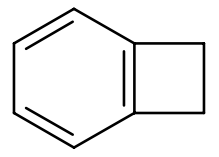

2

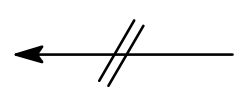<smiles>[X]Cc1ccccc1C[X]</smiles>

1a $(\mathrm{X}=\mathrm{Br})$ b $(\mathrm{X}=\mathrm{Cl})$

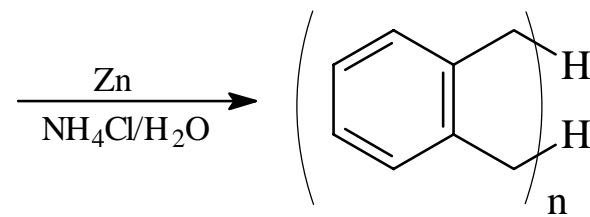

3

More promising results were obtained in the presence of dimethyl fumarate (solubilized with $\mathrm{CH}_{3} \mathrm{CN}$ ): $22 \%$ of the trans-cycloadduct 6 was produced with the dibromide and $53 \%$ with the dichloride. In both cases, polymerisation to $\mathbf{3}$ and reduction of the dienophile to dimethyl succinate were important side reactions (entries 3 and 4). In an attempt to obtain a cleaner reaction and better yield, different temperatures, acidic, neutral and basic salt solutions and several water soluble or unsoluble cosolvents were tried without positive results. Other metals were also tested in different solvent systems: $\mathrm{Mg}, \mathrm{Al}, \mathrm{Mn}$ and Ti gave no cycloadduct at all and $\mathrm{In}, \mathrm{Sn}, \mathrm{Fe}$ and Bi produced only modest yields (15-30\%). Similarly, 15 different transition metal ions and the triphenylphosphine complexes of $\mathrm{Ni}, \mathrm{Pd}$ and $\mathrm{Ru}$ were examined as catalysts in the $\mathrm{Zn}$-promoted reaction. $\mathrm{Cu}$ and $\mathrm{Fe}$ were found to increase the amount of the polymer $\mathbf{3}$ and $\mathrm{Co}, \mathrm{Ni}, \mathrm{Pd}$ and $\mathrm{Au}$ catalyzed the reduction of $\mathbf{1 b}$. The only improvement of the cycloaddition reaction was observed with tris-triphenylphosphine ruthenium(II) dichloride; using $5 \mathrm{mg}$ of this catalyst, the yield of 6 raised to $40 \%$ for the dibromide and $84 \%$ for the dichloride (entries 5 and 6); in the latter case, all side reactions were reduced to a 
few percent. The use of the preformed catalyst was essential, because addition of ruthenium(III) chloride and triphenylphosphine had no effect (entry 7).

Table 1. Reactions of $\alpha, \alpha^{\prime}$-dihalo-o-xylenes (1) and zinc in aqueous medium ${ }^{\mathrm{a}}$

\begin{tabular}{|c|c|c|c|c|c|c|c|c|c|}
\hline \multicolumn{9}{|c|}{ Yields (\%) $^{\mathbf{b}}$} \\
\hline Entry & $\underline{\mathbf{X}}$ & Salt & Dienophile & Cosolvent & Catalyst & Coupling & Reduction & 6 & \multicolumn{7}{|c|}{} \\
\hline 1 & $\mathrm{Br}$ & $\mathrm{NH}_{4} \mathrm{Cl}$ & - & - & - & 65 & 28 & - & - \\
\hline 2 & $\mathrm{Cl}$ & $\mathrm{NH}_{4} \mathrm{Cl}$ & - & - & - & 62 & 25 & - & - \\
\hline 3 & $\mathrm{Br}$ & $\mathrm{NH}_{4} \mathrm{Cl}$ & Dimethyl fumarate & $\mathrm{MeCN}$ & - & 70 & 4 & 22 & 22 \\
\hline 4 & $\mathrm{Cl}$ & $\mathrm{NH}_{4} \mathrm{Cl}$ & Dimethyl fumarate & $\mathrm{MeCN}$ & - & 10 & 36 & 53 & 15 \\
\hline 5 & $\mathrm{Br}$ & $\mathrm{NH}_{4} \mathrm{Cl}$ & Dimethyl fumarate & $\mathrm{MeCN}$ & $\mathrm{Ru}\left(\mathrm{PPh}_{3}\right)_{3} \mathrm{Cl}_{2}$ & 52 & 8 & 40 & 8 \\
\hline 6 & $\mathrm{Cl}$ & $\mathrm{NH}_{4} \mathrm{Cl}$ & Dimethyl fumarate & $\mathrm{MeCN}$ & $\mathrm{Ru}\left(\mathrm{PPh}_{3}\right)_{3} \mathrm{Cl}_{2}$ & 5 & 10 & 84 & 7 \\
\hline 7 & $\mathrm{Cl}$ & $\mathrm{NH}_{4} \mathrm{Cl}$ & Dimethyl fumarate & $\mathrm{MeCN}$ & $\mathrm{RuCl}{ }_{3}+\mathrm{PPh}_{3}{ }^{\mathrm{c}}$ & 15 & 12 & 48 & 10 \\
\hline 8 & $\mathrm{Cl}$ & $\mathrm{K}_{3} \mathrm{PO}$ & Methyl acrylate & $\mathrm{MeCN}$ & $\mathrm{Ru}\left(\mathrm{PPh}_{3}\right)_{3} \mathrm{Cl}_{2}$ & 3 & 12 & 85 & - \\
\hline 9 & $\mathrm{Cl}$ & $\mathrm{K}_{3} \mathrm{PO}$ & Acrylonitrile & $\mathrm{MeCN}$ & $\mathrm{Ru}\left(\mathrm{PPh}_{3}\right)_{3} \mathrm{Cl}_{2}$ & 4 & 13 & 86 & - \\
\hline 10 & $\mathrm{Cl}$ & $\mathrm{K}_{3} \mathrm{PO}$ & Methyl vinyl ketone & $\mathrm{MeCN}$ & $\mathrm{Ru}\left(\mathrm{PPh}_{3}\right)_{3} \mathrm{Cl}_{2}$ & 3 & 5 & 92 & 1 \\
\hline 11 & $\mathrm{Cl}$ & $\mathrm{NH}_{4} \mathrm{Cl}$ & Dimethyl maleate & $\mathrm{MeCN}$ & $\mathrm{Ru}\left(\mathrm{PPh}_{3}\right)_{3} \mathrm{Cl}_{2}$ & 46 & 16 & 37 & 5 \\
\hline 12 & $\mathrm{Cl}$ & $\mathrm{NH}_{4} \mathrm{~F}$ & Methyl crotonate & - & $\mathrm{Ru}\left(\mathrm{PPh}_{3}\right)_{3} \mathrm{Cl}_{2}$ & 60 & 5 & 33 & - \\
\hline
\end{tabular}

${ }^{\mathrm{a}}$ General procedure: see Experimental.

${ }^{\mathrm{b}}$ Determined by ${ }^{1} \mathrm{H}-\mathrm{NMR}$.

${ }^{\mathrm{c}} 2 \mathrm{mg}$ of each were employed.

In the following experiments, the dichloride was reacted under standard conditions with other types of dienophiles. Electron deficient terminal olefins such as methyl acrylate, acrylonitrile and methyl vinyl ketone gave even higher yields of cycloaddition when basic conditions were employed to prevent polymerisation (entries 8-10). Somewhat surprisingly, dimethyl maleate produced only 37 $\%$ of pure cis-substituted cycloadduct (entry 11), probably due to a less favorable overlap in the endo transition state; in a competion experiment using a mixture of dimethyl fumarate and maleate (1 eq. of each), only the former reacted and produced trans-cycloadduct 6. Methyl crotonate was also less reactive, giving the same $33 \%$ yield in the presence or absence of catalyst, and unactivated olefins like 1-heptene, styrene and cyclohexene did not react at all. The observed differences in the reactivity agree with those found in previously reported demetalating reactions [6-8]. However, the aqueous procedure gives much better yields than the electrochemical generation [7], uses unexpensive starting materials, is experimentally simple and avoids the use of DMF, a solvent which is toxic and difficult to dry.

From the mechanistic point of view, the effect of the ruthenium complex is remarkable but not surprising. Indeed, stable o-xylylene complexes of type $\mathbf{5}$ bearing aryldialkylphosphine ligands have 
been synthesized and characterized by x-ray analysis [9]. Furthermore, oxidative decomposition of the exo-complex in the presence of dimethyl acetylenedicarboxylate has produced a cycloadduct in very low yield [10]. This cycloaddition under oxidative conditions and the inexistence of a stable, isolated complex with triphenylphosphine ligands suggest a similar, but less stable intermediate in our reaction, probably in equilibrium with the free o-quinodimethane 4 (scheme 1). The complexation may prevent the polymerisation of $\mathbf{4}$, increasing thus its lifetime. Highly reactive dienophiles probably react rapidly with the complex 5 or with free $\mathbf{4}$. Less reactive olefins need free $\mathbf{4}$ and have to compete with the polymerisation reaction; for this reason no improvement is observed in the presence of the catalyst. Benzocyclobutene (2) can be excluded as a possible intermediate because it was recovered unchanged in control experiments in the presence or absence of catalyst.

\section{Scheme 1}

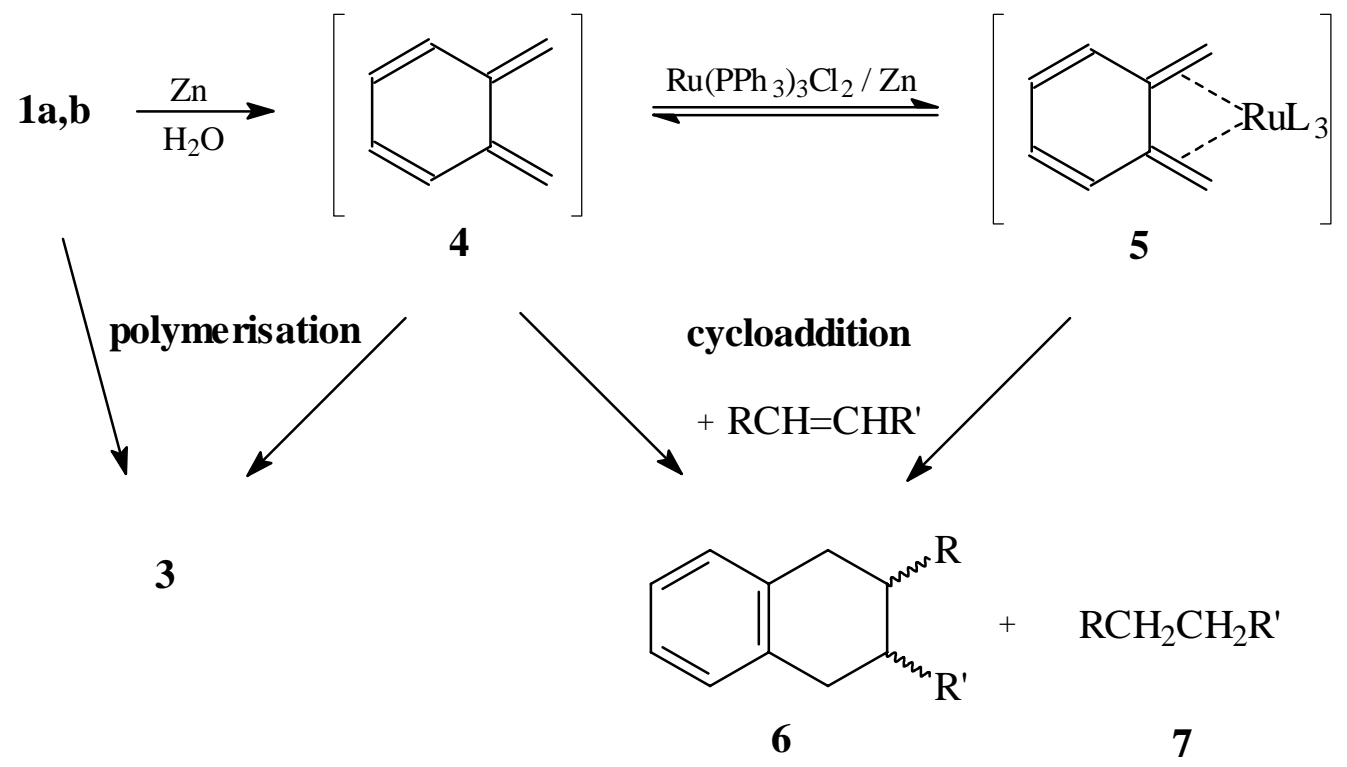

\section{Conclusions}

In conclusion, the generation of o-quinodimethane (4) in aqueous medium is a very simple and high yielding alternative for intermolecular cycloadditions to activated dienophiles, especially when catalized by the ruthenium complex. The reaction represents the first example of a one-step cyclisation using dihalo compounds and zinc in aqueous medium.

\section{Acknowledgements}

This work was supported by CNPq (Brasilia). We thank Ms. Érida M.A. Pequeno for GC/MS analyses. 


\section{Experimental}

\section{General}

In all experiments commercially available reagents and solvents were used without further purification or activation. The cycloadducts obtained in preparative yields (entries 6, 8-10) showed physical and spectroscopic properties in perfect agreement with previously reported data [6-8, 11].

Reaction of $\alpha, \alpha^{\prime}$-dihalo-o-xylenes (1) with zinc in the presence or absence of dienophiles

To $2 \mathrm{~mL}$ of saturated aqueous salt solution (see Table 1 ) a mixture of $\mathbf{1}$ (0.5 mmol), dienophile $(0.6 \mathrm{mmol})$, catalyst $(5 \mathrm{mg})$ and $0.5 \mathrm{~mL}$ of $\mathrm{CH}_{3} \mathrm{CN}$ was added at r.t. Under vigorous stirring zinc dust $(1.0 \mathrm{mmol})$ was added portionwise over a period of $10 \mathrm{~min}$. After $1 \mathrm{~h}$, the mixture was hydrolysed with $2 \mathrm{~N} \mathrm{HCl}$, extracted with $1 \mathrm{~mL}$ of $\mathrm{CCl}_{4}$ containing $0.05 \mathrm{mmol}$ of cyclohexane as internal quantitative reference. The crude extracts were analysed by ${ }^{1} \mathrm{H}-\mathrm{NMR}$ and GC/MS. In preparative runs, the products were purified by $\mathrm{CC}$ and crystallisation.

\section{References and Notes}

1. Reviews: (a) W.Oppolzer, Synthesis 1978, 793-802. (b) R.L. Funk and K.P.C. Vollhardt, Chem. Soc. Rev. 1980, 9, 41-61.

2. C.R.Flynn and J. Michl, J. Am. Chem. Soc. 1974, 96, 3280-3288.

3. (a) C.-J. Li and T.H. Chan, Organic Reactions in Aqueous Media, John Wiley \& Sons, New York, 1997. (b) C.-J.Li, Tetrahedron 1996, 52, 5643-5668. (c) A. Lubineau, J. Augé, Y. Queneau, Synthesis 1994, 741-760.

4. L.W. Bieber and I. Malvestiti, unpublished results.

5. L.W. Bieber, E.C. Storch, I. Malvestiti and M.F. Silva, Tetrahedron Lett. 1998, 39, 9393-9396.

6. K. Alder and M. Fremery, Tetrahedron 1961, 14, 190-200.

7. E. Eru, G.E. Hawker, J.H.P. Utley and P.B. Wyatt, Tetrahedron 1995, 51, 3033-44.

8. H. Sato, N. Isano, I. Miyoshi and M. Mori, Tetrahedron 1996, 52, 8143-58.

9. M.A. Benett, Coord. Chem. Rev. 1997, 166, 225-254.

10. C.L.Skerratt,S.D. Chappell, R.D. Bowen, R.C. Storr and D.J.Cole-Hamilton, Polyhedron 1986, 5 , 1035-1036.

11. R.D. Haworth and F.H. Slinger, J. Chem. Soc. 1940, 1321-27.

Samples Availability: Not available.

(C) 2001 by MDPI (http://www.mdpi.org). Reproduction is permitted for non commercial purposes 